\title{
Impact of New Public Transportation System in Nagpur City: A Review
}

\author{
Narendra M.Hatwar * ,Prof .V. K. Gajghate ** \\ ${ }^{I}$ Civil Engineering Department, M-Tech Transportation G.H.Raisoni College of Engineering Nagpur \\ Maharashtra, India \\ ${ }^{2}$ Assistant professor Civil Engineering Department G. H. Raisoni College of Engineering Nagpur Maharashtra, \\ India
}

\begin{abstract}
This paper regards to impact of new public transportation system NPTS includes public transportation is the most efficient method to solve city transportation solution such as public traffic jam, simultaneously traffic incidents, traffic environment pollution and energy sources deficiency etc. For designing city-bus intelligent system Nagpur city, the main body in ITS (Intelligent Transportation System), we analyzed the complete demand of society, and government, passenger, driver and center of monitoring and management. City-bus control traffic system the evaluations of the travelling time at the connection stop are the main objective of this study. In Nagpur city most public transportation runs to schedules timetable with the most frequent services running to headway. This facilities shift from car traffic towards public transportation, which is safer, cleaner and produces less congestion.
\end{abstract}

Key word: Public transportation network, Intelligent Transportation system The timed management, schedule of city bus with withdrawal to taken, discrete waiting and travelling times of city.

\section{Introduction}

Public transportation system evaluation and the optimization of the travelling times of passenger in public transportation systems is a primary purpose in our research at the time. With the growing interest and the increasing demand. Such as transportation area becomes more and more important. The main objectives in transportation system.

A] Exploitation of these system capacities in order to ensure a general reliability of this system and comfort for passenger.

B] Minimization of the connection time at interchange point and operational cost. Public Transport is the mass transportation of people from one place to another place through city Bus, Rail, and metro, with efficient speed, punctuality, frequency, facilities, comfort, convenience, and reliability. Public transportation or public transit is a shared passenger transport service which is available for use by the general public, as distinct from modes such as hired buses, metro rails, local trains which are not shared by strangers without private. Most public transport runs to a scheduled timetable with the most frequent service running to headway. To ensure accessibility and live ability of city for future generations however, a substantial quality leap in public transportation is compulsory. This will facility a desired modal shift from car traffic towards public transportation which is safer, cleaner and yield less congestions.

Driver- lessening driving tiredness, monitoring driving status (including driver and city-bus), enhancing relevancy and time order to vehicle control. Center of monitoring and management: monitoring city bus transportation status, scheming reasonable transportation route, enhancing the controllable ability of transportation. Based on complete request analysis, city-bus intelligent control system is divided into three different but correlative request layers: IS (Intelligent Service), IM (Intelligent Management) and IC (Intelligent Control). Design of city-bus intelligent control system must aim at these three request layers. City-bus intelligent control system request relationship.

Intelligent Service - intelligent service is the target of city-bus intelligent control system. Based on whole request analysis and different service objects, city-bus intelligent control system should achieve service function as follows. Society and government: low floor, low gas consumption, low exhaust emission, low pollution, high intelligent control, high reliability, high comfort, high efficiency etc.Passenger vehicle security, in-vehicle multimedia, route direction, traffic status, in-vehicle communication tool, electronic charge etc.Driver: driver status monitoring, vehicle driving status monitoring, vehicle ability of avoiding danger, intelligent control of driving and braking system, intelligent control of vehicle body system, traffic status etc.Center of monitoring and management: remote control, vehicle flow status, passenger flow status, charge status etc. 
Intelligent Management- Intelligent management is the basis of city-bus intelligent control system. According to the request of intelligent management, city-bus intelligent control system should receive different data from in-vehicle sensor and remote monitoring center. By storing data in to database.

Intelligent Control System- As a result showed drivers can avoid 60\% tail collision incident, $30 \%$ head collision incident and 50\% road incident if they receive 0.5 second alert signal before collision. Specially, if they have 1 second alert time, 90\% incident can be avoided. In security alert intelligent control system can be divided in to driver monitoring alert control system, vehicle driving status alert control system and vehicle emergent avoiding danger system. This system uses kinds of signal collection devices such as detector, scanner and so on to obtain alert parameters. With real-time information.

The purpose of study is to introduce:-

\section{Need of study-}

1) Transport system in cities for sustainable transportation planning. The need of the study is to introduce public transport system in Nagpur city for selected at the initial stages of its development.

2) It is a worldwide phenomenon that more and more people are living in cities and towns. Public transportation is often the only available affordable means of transportation for immigrants, especially in their are first few months after arrivals. Transit systems in small cities struggle to maintain ridership levels high enough to continue receiving local subsidies.

3) The last few decades have shown a substantial increase in personal mobility. Not only in interurban travel but as well in the urban environment traffic and transport volume have been increasing for year.

4) To ensure accessibility and livability of our cities for future generations however, a substantial quality leap in public transport is necessary.

5) Development guidelines to help to plan develop and implement effective and efficient public transportation systems in Nagpur City.

\section{Literature Review}

The literature review on Public Transportation system, with particular emphasis on planning procedure. Today the cities are residence to half of the world's population, and in $2030,60 \%$ of the population will live in a city. The urban areas have an increasing importance in our society as they are continually growing, along with all the issues related to theme. Many metro Politian cities in India are facing problem as the ones related to urban transportation, and their interrelated impacts on the environment, economical and society's are always getting bigger as the cities are growing in their size and populations. Roads and rails respective are first and second largest land consumers and cause several negative consequences such as pollution, subsequent healthrelated problems, traffic congestion or accidents. Implementing more sustainable transportation systems within human settlements is principal fundamental in order to limit those issues related to transportation. This can also have positive impacts on the city for itself. Determining the level of service of a transit network is a difficult task. There are two reasons. First, the number of factors related to service quality, such as walking distance, invehicles travel times, waiting time, number of destination serve and number of transfers needed to reach destinations makes transit connectivity a multidimensional problems. And the transits system consist of many distinct route. Determining the extent to which the routes are integrated and coordinated so that the transit system is connected. The structure of the public transit network is critical in determining performance, coverage, and service of the network.

\section{Andreas person, "Public transportation in small towns area with great potential," Lund Institute Of Technology Sweden.}

The important aims of the project are to find the similarities and differences between the conditions in small and large towns and to find a suitable planning strategy for the small town's traffic. In Hässleholm and Ängelholm, two small Swedish towns with about 18000 and 22000 inhabitants respectively, the bus systems were changed in July 2001. The main idea was to provide traffic with higher frequency. In Hässleholm the routes were also changed and the central bus terminal was moved to a more attractive location. The number of passengers has increased since the changes and this was studied using time, series analysis. An inquiry was also carried out among the passengers aiming to find attitudes about the changes.

Peter King. (1997) "Switching To Public Transport: Results of A UITP Trial" The project aimed to increase public transport use through personalized marketing directed at people who had little knowledge of the public transport network and made little use of it.

Margareta Fireman, (2009) "Customer Satisfaction in Public Bus Transport- A study of travelers' perceptions Indonesia, "Karlstad Universities Springs. An increases in population generates increasing in travel demand. An increased road length and new roads generate faster and longer trip, more trip by the car and 
higher car ownership all of which adds up to more traffic congestion and pollution. Public transportation operator is forced to place emphasis on the monitoring and improvements of the services provided in an attempt to address the increasing rate of car ownership. His study focuses public transport users' satisfaction.

John Puncher., (2004) "The Crisis of Public Transport in India: Overwhelming needs the rapid growth of India's urban population has put enormous strains on all transportation systems. Burgeoning travel demand for overdo the limited supply of transport infrastructure and service. Public transportation, in particulars, has been completely overwhelmed. Mostly buses and trains service is overcrowd, in dependable, slow, inconvenient, and risky. Moreover, the public ownership and operation of most public transport services has greatly reduced productivity and inflated cost. India city desperately need improve and expanded public transportation services. Unfortunately, meager government financials assistance and the complete lack of any assistive policies, such as traffic priority for buses, place public transport in an almost unsolvable situation.

Maria Attar. (2012) "Reforming the urban public transport bus system in Malt Instead, an organic growth alongside the main routes linking new areas to the public transportation network and a declining level of service pushed even more the local population to switch to private mobility. This has classified the islands between the countries in the world with the highest levels of motorization.

\section{Jenny Carlson, (2010) "Passengers' Valuation of Quality in Public Transport with Focus on Comfort" Chalmers University Of Technology, Sweden.}

In this project, it has been investigated how passengers valuate comfort on board local and regional buses in the region of Gothenburg's. The Gothenburg's region is facing challenge considering how to manage a population increase and at the same time achieve sustainable infrastructure developments. Measure is therefore requiring to attract new passenger as well as to keep the people that already use the public transport system. One factor that car users point out as the main reason for travelling by car instead of with public transport is comfort. Qualitative phone interviews were performed in order to get a deeper understanding about how public transport trips are experienced in a larger perspective. Older respondents consider comfort as more important than younger respondents. Women think that the comfort standard on board is better and at the same time more important than men.

\section{Surveys \& Data Collection}

Traffic volume studies are conducted to determine the number, movement, and classification of roadway vehicle at a given locations. These are data can help identifies critical flows time period, determine the influence of large vehicle or pedestrian on vehicular traffic flows or document of traffic volume trends. The length of the sampling period depends on the type of count being taken and the intended use of the data recorded.

Two methods are available for conducted traffic volume counts

- Manual

- Automatic

Manual counts are typically used to gather data for determination of vehicle classification, turning movement, direction of travel, pedestrian movement, or vehicle occupancy. Most application of manual count required small sample of data at any given location. Manual count is typically used for periods of less than days. Normal interval for a manual counts are 5, 10, or 15 minute. Traffic count during a Monday morning rush hour and a Friday evening rush hour may show exceptionally high volume and are not normally used in analysis. Therefore, count is usually conducted on a Tuesday, Wednesday and Thursday.

\section{- Automatic}

Automatic counts are typically used to gather data for determine of vehicle hourly pattern, daily or seasonal variation and growth trends, or annual traffic estimate. The automatic count method provides a means for gathering large amount of traffic data. Automatically count is usually taken in 1- hour's interval for each 24hour's period. The count may extends for a week, months, or year. When the count is recorded for each 24hours time period, the peak flow period can be identified. The selection of study method should be determined using the counts period. The count period should be representatively of the time of days, day of months, and month of years for the study area. The count period should avoid special event or compromising weather conditions Counts period may ranges from 5 minute to 1 year. Typical counts period are 15 minutes or 2 hours for peak period, 4 hours for morning and afternoon peak 6 hour for morning, midday, and afternoon peak, and 12 hours for daytime period For example, if you were conducting a 2 -hour peak period counts, eight 15-minute counts would be required. 


\section{Map On Nagpur City}

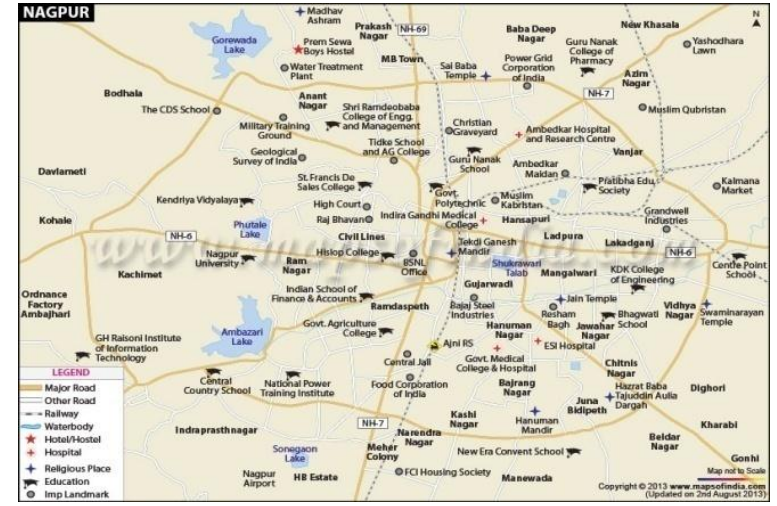

\section{Location Of Area Network}

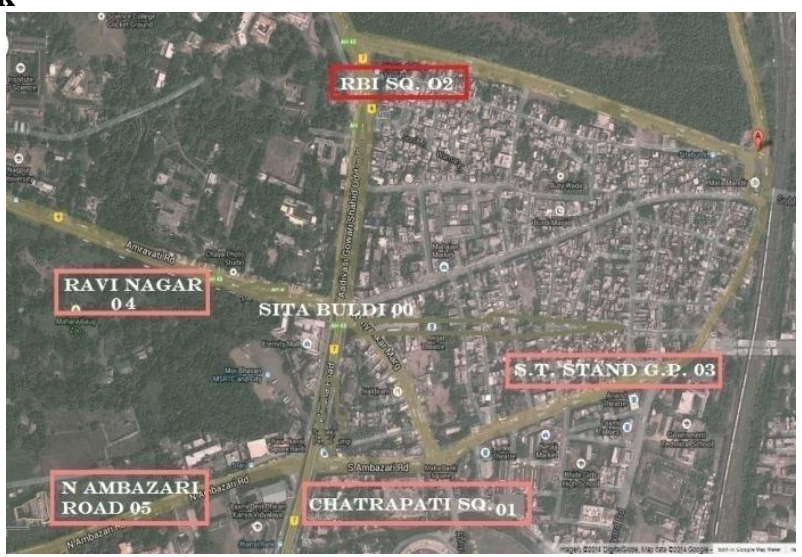

Nagpur is a city and a municipality in Metropolitan Region in the state of Maharashtra, India. Nagpur is one of the primaries Satellite Tow Metropolitan Region. The study area is selected as Nagpur, Maharashtra, India. A network is selected in the city on which four corridors which connects of the city and traffic flow on the city corridors are selected. Nagpur is a city with population covers an Area of 50 sq.km. The network has been selected and modified to a typical network which is applicable for Indian small scale cities having same demographic and physical features as Nagpur.

Selection Of Network-

\begin{tabular}{|l|l|l|}
\hline $\begin{array}{l}\text { Sir } \\
\text { No. }\end{array}$ & \multicolumn{1}{|c|}{ Corridor } & $\begin{array}{l}\text { Distance In( } \\
\text { Km) }\end{array}$ \\
\hline 1) & Sitabuldi-Chatrapati & 4.5 \\
\hline 2$)$ & Sitabuldi-Rbi Sq & 1.5 \\
\hline 3$)$ & Sitabuldi-(S.T.Stand)Ganesh Peth & 3.0 \\
\hline 4$)$ & Sitabuldi-Ravinagar & 3.5 \\
\hline
\end{tabular}

Corridor-1 Sitabuldi To Chatrapati-

\begin{tabular}{|l|l|l|l|l|l|l|l|}
\hline Time & $2 \mathrm{w}$ & $3 \mathrm{w}$ & $4 \mathrm{w}$ & Buses & Bicycle & Lmv & Volume \\
\hline $9.00 \mathrm{am}-9.15 \mathrm{am}$ & 267 & 35 & 29 & 12 & 4 & 7 & 354 \\
\hline $9.15 \mathrm{am}-9.30 \mathrm{am}$ & 218 & 38 & 36 & 11 & 7 & 5 & 315 \\
\hline $9.30 \mathrm{am}-9.45 \mathrm{am}$ & 234 & 28 & 38 & 9 & 3 & 9 & 321 \\
\hline $.45 \mathrm{am}-10.00 \mathrm{am}$ & 256 & 43 & 28 & 13 & 5 & 4 & 349 \\
\hline $5.00 \mathrm{pm}-5.15 \mathrm{pm}$ & 176 & 25 & 46 & 9 & 11 & 10 & 277 \\
\hline $5.15 \mathrm{pm}-5.30 \mathrm{pm}$ & 243 & 34 & 27 & 14 & 9 & 12 & 339 \\
\hline $5.30 \mathrm{pm}-5.45 \mathrm{pm}$ & 321 & 38 & 42 & 15 & 12 & 8 & 436 \\
\hline $5.45 \mathrm{pm}-6.00 \mathrm{pm}$ & 297 & 41 & 38 & 17 & 3 & 13 & 409 \\
\hline
\end{tabular}

Corridor 2- Sitabuldi To R.B.I .Sq-

\begin{tabular}{|l|l|l|l|l|l|l|l|}
\hline Time & $2 \mathrm{w}$ & $3 \mathrm{w}$ & $4 \mathrm{w}$ & Buses & $\begin{array}{l}\text { Bicyc } \\
\text { le }\end{array}$ & Lmv & $\begin{array}{l}\text { Volu } \\
\text { me }\end{array}$ \\
\hline $\begin{array}{l}\text { 9.00am- } \\
\text { 9.15am }\end{array}$ & 243 & 32 & 36 & 8 & 10 & 12 & 341 \\
\hline
\end{tabular}




\begin{tabular}{|l|l|l|l|l|l|l|l|}
\hline $\begin{array}{l}9.15 \mathrm{am}- \\
9.30 \mathrm{am}\end{array}$ & 218 & 38 & 36 & 11 & 13 & 9 & 325 \\
\hline $\begin{array}{l}9.30 \mathrm{am}- \\
9.45 \mathrm{am}\end{array}$ & 234 & 28 & 38 & 14 & 12 & 7 & 333 \\
\hline $\begin{array}{l}9.45 \mathrm{am}- \\
10.00 \mathrm{am}\end{array}$ & 256 & 43 & 28 & 12 & 11 & 6 & 356 \\
\hline $\begin{array}{l}5.00 \mathrm{am}- \\
5.15 \mathrm{pm}\end{array}$ & 176 & 47 & 46 & 9 & 14 & 10 & 302 \\
\hline $\begin{array}{l}5.15 \mathrm{pm}- \\
5.30 \mathrm{pm}\end{array}$ & 243 & 34 & 27 & 7 & 9 & 5 & 325 \\
\hline $\begin{array}{l}5.30 \mathrm{pm}- \\
5.45 \mathrm{pm}\end{array}$ & 321 & 38 & 42 & 10 & 15 & 11 & 437 \\
\hline $\begin{array}{l}5.45 \mathrm{pm}- \\
6.00 \mathrm{pm}\end{array}$ & 297 & 41 & 38 & 13 & 16 & 12 & 417 \\
\hline
\end{tabular}

Corridor-3 Sitabuldi To Ganeshpeth-

\begin{tabular}{|l|l|l|l|l|l|l|l|}
\hline Time & $2 \mathrm{w}$ & $3 \mathrm{w}$ & $4 \mathrm{w}$ & Buses & Bicycle & Lmv & Volume \\
\hline $\begin{array}{l}9.00 \mathrm{am}- \\
9.15 \mathrm{am}\end{array}$ & 298 & 35 & 41 & 12 & 14 & 11 & 411 \\
\hline $\begin{array}{l}9.15 \mathrm{am}- \\
9.30 \mathrm{am}\end{array}$ & 249 & 38 & 36 & 14 & 10 & 9 & 356 \\
\hline $\begin{array}{l}9.30 \mathrm{am}- \\
9.45 \mathrm{am}\end{array}$ & 312 & 32 & 37 & 16 & 13 & 12 & 422 \\
\hline $\begin{array}{l}9.45 \mathrm{am}- \\
10.00 \mathrm{am}\end{array}$ & 322 & 43 & 32 & 11 & 16 & 10 & 434 \\
\hline $\begin{array}{l}5.00 \mathrm{pm}- \\
5.15 \mathrm{pm}\end{array}$ & 176 & 35 & 34 & 13 & 12 & 7 & 277 \\
\hline $\begin{array}{l}5.15 \mathrm{pm}- \\
5.30 \mathrm{pm}\end{array}$ & 243 & 34 & 27 & 10 & 9 & 11 & 534 \\
\hline $\begin{array}{l}5.30 \mathrm{pm}- \\
5.45 \mathrm{pm}\end{array}$ & 332 & 38 & 33 & 15 & 17 & 7 & 442 \\
\hline $\begin{array}{l}5.45 \mathrm{pm}- \\
6.00 \mathrm{pm}\end{array}$ & 345 & 37 & 29 & 12 & 15 & 9 & 447 \\
\hline
\end{tabular}

Corridor- 4 Sitabuldi To Ravinagar

\begin{tabular}{|l|l|l|l|l|l|l|l|}
\hline Time & $2 \mathrm{w}$ & $3 \mathrm{w}$ & $4 \mathrm{w}$ & Buses & Bicycle & Lmv & Volume \\
\hline $\begin{array}{l}9.00 \mathrm{am}- \\
9.15 \mathrm{am}\end{array}$ & 312 & 35 & 32 & 14 & 12 & 7 & 412 \\
\hline $\begin{array}{l}9.15 \mathrm{am}- \\
9.30 \mathrm{am}\end{array}$ & 365 & 28 & 39 & 12 & 14 & 11 & 469 \\
\hline $\begin{array}{l}9.30 \mathrm{am}- \\
9.45 \mathrm{am}\end{array}$ & 276 & 43 & 28 & 15 & 16 & 9 & 387 \\
\hline $\begin{array}{l}9.45 \mathrm{am}- \\
10.00 \mathrm{am}\end{array}$ & 322 & 29 & 33 & 17 & 11 & 12 & 424 \\
\hline $\begin{array}{l}5.00 \mathrm{pm}- \\
5.15 \mathrm{pm}\end{array}$ & 233 & 34 & 36 & 19 & 10 & 13 & 345 \\
\hline $\begin{array}{l}5.15 \mathrm{pm}- \\
5.30 \mathrm{pm}\end{array}$ & 323 & 38 & 39 & 16 & & 10 & 433 \\
\hline $\begin{array}{l}5.30 \mathrm{pm}- \\
5.45 \mathrm{pm}\end{array}$ & 297 & 41 & 38 & 12 & 12 & 9 & 409 \\
\hline $\begin{array}{l}5.45 \mathrm{pm}- \\
6.00 \mathrm{pm}\end{array}$ & 257 & 36 & 34 & 11 & 8 & 14 & 326 \\
\hline
\end{tabular}

\section{Objective-}

- To conduct Preliminary survey

- To selection of suitable corridor.

- Developing possible Network for Public transportation corridors.

- Estimating Travel Cost (Vehicle operation Cost) using IRC: SP: 30-2009.

\section{Conclusion}

The city will increase their role in the future due to the growth of their dweller, side by side with the increase of their urban issues. Many problems today have their foundation or its bigger share in the cities, thus the cities must be seen as the solutions to these problems. The estimate travel time, Speed before and after introducing public transport in size city through simulation and IRC standards. This Dissertation has investigated a new PT introduction in cities which may lead to sustainable transport and reduce congestion problems in future. 


\section{Future scope of work -}

The present works leave a wide scope for futures investigation listed below to explore many aspects in obtaining more scenarios

Change in land use pattern which may be responsible for introducing BRTS can be considered.

Dedicated corridor for buses (BRTS) condition can be considering other parameter, shift and fleet size can be calculated.

\section{References-}

[1] Johan Holmgren., "Study in Local Public Transportation Demand", Linkoping Studies in Art and Science, 2008.

[2] Margareta Fireman., "Customer Satisfaction in Public Bus Transportation- A study of travel' perception in Indonesia", Karlstad University Spring, 2009.

[3] Jenny Carlson., "Passengers' Valuation of Quality in Public Transportation with Focus on Comfort", Chalmers University of Technology, 2012

[4] Gee tam Tiara. "Sustainable Transportation Systems Linkage between Environmental Issues, Public Transportation, Non Motorized Transportation and Safety", Economic and Political Weekly, 1999.

[5] Vatic, V, Urban transits: planning, operation and economics, Wisely, I Madcap, G. Badami.,"An analysis of public bus transits performance in Indian city", Transportation, 2007.

[6] Maria Attars., "Reforming the urban public transportation bus system in Malta: Approach and acceptance", Institutes for Sustainable Development, 2012.

[7] Alvaro Costa., Ruben Fernandez., "Urban public transport in Europe: Technology diffusion and market organization", Transportation Research, 2012.

[8] P Meese., "Public transportation network planning: a guide to best practice in NZ cities", New Zealand Transportation Agency, 2010.

[9] David Neyonsenga., "Assessing Public transportation supply for Kigali, Rwanda", 2012 